\title{
ASPECTOS DA IMPROVISAÇÃO TEATRAL NA FRANÇA
}

\author{
Patrícia de Borba (Pita Belli) ${ }^{1}$
}

\section{Resumo}

Este artigo busca identificar como a Improvisação Teatral foi pensada por Jacques Copeau e seus colaboradores, Charles Dullin e Louis Jouvet, e posteriormente, como se dão suas práticas na escola criada por Jacques Lecoq que têm forte influência das idéias de Dullin, principalmente em relação ao papel da Improvisação no treinamento do ator.

Palavras-chave: improvisação, treinamento, teatro francês.

\begin{abstract}
This article intends to identify how the Theatrical Improvisation was thought by Jacques Copeau and his collaborators, Charles Dullin and Louis Jouvet, and later, how its practices took place in the school created by Jacques Lecoq who suffered a strong influence of Dullin's ideas, mainly in relation to the role of the Improvisation in the actor's training.
\end{abstract}

Keywords: improvisation, training, French theater.

Jacques Copeau foi a inspiração da reforma que se iniciou na arte teatral de inícios do século XX na França, assim como Stanislavski foi o responsável pelas profundas mudanças que ocorreram no teatro russo. Anne Neuschäfer, em seu artigo intitulado Jacques Copeau $e$ O Théâtre du Soleil, comenta:

\section{Se Un Essai de Rénovation [Uma Tentativa de} Renovação] foi o manifesto, ainda abstrato, desse renascimento teatral - uma espécie de contrato ainda não preenchido com relação ao futuro - ese a primeira temporada do Vieux Colombier apresentou encenações de peças escritas, clássicas e contemporâneas, nem por isso as reflexões do grupo pararam por aí. Não os abandonou a visão de um espetáculo ao mesmo tempo elaborado e rapidamente modificável, e ela se concretizou à medida que o trabalho teatral se precisou. (NEUSCHÄFER, 1995, p. O1)
${ }^{1}$ Professora das disciplinas de

Improvisação e

Prática de Montagem, coordenadora do FITUB, diretora do Grupo Teatral Phoenix, coordenadora da Especialização em Encenação Teatral, editora da revista 0 Teatro Transcende - FURB; diretora do Grupo Fãs de Teatro; doutoranda em Teatro no Programa de Pós-Graduação UDESC. 
Tendo fundado o teatro do Vieux Colombier em 1913, junto ao qual, mais tarde, em 1920, abriu finalmente a escola que tanto almejava, Copeau, assim como o mestre russo, também acreditava ser a Improvisação um instrumento para a formação do ator, e também como Stanislavski, intentou um teatro improvisado. Em 1915 visitou a Itália onde conheceu Gordon Craig, que lhe mostrou diversos documentos sobre a Commedia dell'arte. Também na ocasião observou o trabalho do cômico Ettore Petrolini, que lhe pareceu uma encarnação moderna de tal estilo de representação. Tudo isso despertou nele um grande interesse pela Improvisação. Além do que, atento a tudo que se passava ao seu redor, não deixou de observar as formas improvisadas que subsistiam no music hall, nos palhaços de circo, e mesmo nos vendedores de rua.

Com a guerra, as atividades do Vieux Colombier ficaram interrompidas. Alguns atores se encontravam na frente de batalha, entre eles Charles Dullin e Louis Jouvet - que na ocasião ainda se chamava Jouvey e depois viria a ser um dos mais renomados atores do teatro francês -, ambos colaboradores de Copeau, e com os quais estabeleceu uma assídua correspondência cujo assunto girava em torno da Improvisação, que na época àqueles também interessava sobremaneira. Alguns trechos dessa correspondência se encontram publicados na revista Máscara, edição de 1996-1997. Copeau transcreveu as cartas em seu caderno e a elas juntou observações e comentários pessoais. E através desses comentários podem ser observadas algumas preocupações dele, que giravam em torno de dois aspectos diferentes. Um deles se referia ao ensino do teatro para os jovens, a quem se dedicou com muito afinco durante praticamente toda a sua vida, e outro em relação à formação de um grupo capaz de representar all'improviso, que contaria com a presença de seus colaboradores. Em carta endereçada a Louis Jouvet no inverno de 1916, Copeau escreve sobre esse novo gênero, que deveria basear-se em "tipos" contemporâneos:

Inventar uma dezena de personagens modernos, sintéticos, de grande extensão, que representem caracteres, defeitos, paixões, ridículos morais, sociais, individuais, de hoje. Inventar os seus figurinos, sempre idênticos, modificados apenas conforme as circunstâncias, por um tipo acessório. [Depois,] confiar a dez atores essas dez personagens de uma Comédia autônoma que compreende todos os gêneros, da pantomima ao drama. Cada ator tem a própria personagem, que é propriedade sua, que se torna ele mesmo, que ele próprio alimenta, com os seus sentimentos, com as suas observações, com a sua experiência, com as suas leituras, com as suas invenções. Eis a grande descoberta (tão simples!), a grande revolução, ou melhor: o retorno, grande e majestoso, à mais antiga tradição. (NEUSCHÄFER, 1995, p. 01) 


\section{Urdimento}

Ademais, nos dois casos, para Copeau, a Improvisação seria capaz de dar ao ator flexibilidade e espontaneidade na utilização do gesto e da palavra, necessários à manutenção do vigor da cena. E para o treinamento através dela, acreditava que manter os jovens atores - aqueles da escola que por fim abriria em 1920-distantes do tex to previamente escrito, estimularia a espontaneidade, a "naturalidade". Para este caso, os jogos associativos sugeridos por Jouvet, receberam sua aprovação. Jouvet sugeria, em sua carta de 10 de janeiro de 1916, o uso de antigos manuais de oratória e de gesticulação, para utilização em jogos de associações de idéias, uma espécie de ginástica intelectual. Sugeria também alguns jogos de sociedade que poderiam desenvolver tais associações. Para essas sugestões, Copeau anotou: "Sua idéia do “jogo para desenvolver a associação de idéias, a facilidade de respostas’ é excelente. Bastará desenvolver para fazer dela um método fecundo" ${ }^{2}$ (COPEAU, 1996-1997, p. 46).

Ainda para os atores jovens, Copeau aceitou com entusiasmo a proposta que Jouvet fez em outra carta, datada de 31 de janeiro do mesmo ano, em que sugere que alguns textos poderiam ser "reanimados", "regenerados" por exercícios que consistiriam em reduzi-los a um roteiro, uma espécie de esqueleto de ações, sobre o qual os atores improvisariam. Seria, talvez, uma maneira de rejuvenescer os clássicos, ou, ao menos, de fazer com que os atores não representassem de maneira mecanizada, segundo influências anteriores. Dessa maneira, o diretor estaria estimulando a imaginação dos atores e não apenas tentando simplificar o texto para deixá-lo mais claro, não teria senão que corrigir e dirigir atores "vivos".

Para Copeau, a preocupação com a renovação, a regeneração, estava na raiz de suas propostas de utilização da Improvisação na preparação dos atores, motivo que o fez afirmar que, com certeza, essas sugestões fariam parte de seu método para a formação dos jovens, deixando bem claro o mérito de Jouvet nessa contribuição. É conveniente lembrarmos que Mikhail Tchekhov, em seu livro Para o ator, que só foi publicado em 1953, nos Estado Unidos, segue a mesma linha de pensamento ao perceber o uso da Improvisação como ferramenta para dar "frescor" aos textos clássicos.

Ao se referir ao treinamento para os atores com vistas ao teatro improvisado, Copeau expressou sua preocupação em que os exercícios não fossem calcados, de antemão, em textos ou investigações teóricas, mas na livre manifestação do indivíduo. Em contrapartida às sugestões de Jouvet de um estudo minucioso sobre os cômicos italianos, época a época, para dar embasamento à Improvisação, Copeau observou que seu entusiasmo o estava induzindo ao erro, procurando abraçar meios que não seriam diretos, vivos. Acreditava que a primeira investigação deveria ser sobre as qualidades, sobre as habilidades pessoais e sua natureza com o uso da observação direta sobre

2 "Su Idea del "juego para desarrollar la asociación de ideas, la facilidad de respuestas' es excelente. Bastará desarrollar para hacer de ella un metodo fecundo" 


\section{Urdimento}

3"Lo que está dado es el actor, quien con su físico, sus medios y su naturaleza, encarna a un personaje. El procedimiento científico, la erudición genealógica no cuentan sino después, para enderezar, enriquecer y reforzar el estilo." a realidade. "O que está dado é o ator, o qual, com seu físico, seus meios e sua natureza, encarna um personagem. O procedimento científico, a erudição genealógica não contam senão depois, para encaminhar, enriquecer e reforçar o estilo"3 (COPEAU, 1996-1997, p. 47).

Em correspondência datada de 9 de fevereiro do mesmo ano, Jouvet propunha, para os exercícios de Improvisação, que eles girassem diversas vezes em torno de um mesmo tema, até que se pudesse ter facilidade em trabalhar com tal assunto. Dessa maneira, cada um poderia ir acumulando um repertório de materiais e aprimorando esse repertório para dele lançar mão quando necessitasse em cena, assim como o faziam os atores da Comemdia dell'Arte. Essa referência está diretamente ligada ao fato de que Copeau, juntamente com Jouvet, Dullin e outros colaboradores, para além da utilização dos exercícios de Improvisação para a preparação dos atores, como já foi mencionado, tinha a intenção de montar um grupo que representasse all'improviso. No entanto, essa intenção não era a de reproduzir um estilo de teatro anteriormente praticado pelos atores ítalo-franceses, mas de dar-lhe nova vida, levando em consideração o chamado de uma necessidade pessoal interior, num tempo e espaço outros. Além disso, também de tal experiência poderiam resultar bons atores, cuja herança do ensino nos Conservatórios, considerada por Jouvet como "fossilizadora" (COPEAU, 1996-1997, p. 45), poderia ser finalmente renovada.

Copeau pensava nos personagens dessa "nova comédia" como "sobrinhos-netos" dos antigos personagens da Commedia dell'arte. Cada ator se encarregaria de estudar um personagem, aprofundar-se nele. Trariam mesmo consigo alguns detalhes de seus "antepassados”, mas com o devido cuidado para que se estabelecessem nesse novo tempo. Sugeria que os atores praticassem seus personagens a qualquer momento, nos passeios, nas refeições, até que se construísse o caráter de cada um. Daí poderia surgir uma criação coletiva. No entanto, Copeau assegurava que as informações a serem dadas aos atores sobre a tradição do teatro italiano de estilo improvisado deveriam ser dadas por ele mesmo, na medida em que julgasse necessário, para salvaguardar a vivacidade das representações, assim como acreditava que quando se improvisa a partir de textos dados, a tendência é a reprodução. O ator, provavelmente, tentaria lembrar-se ao invés de tentar inventar. Quanto às expectativas do teatro all'improviso que propunha, com base na criação, pelos próprios atores, de personagens fixos, Copeau acreditava que a partir de determinado momento os personagens se desenvolveriam independentemente e que os argumentos se engendrariam por si mesmos. Vislumbrava que essa nova comédia, caso obtivesse êxito, superaria todos os demais gêneros, assim como seria responsável por devolver a liberdade à imaginação criadora, à "fantasia 
dramática". Haveria de ser uma criação autêntica, um gênero diferente que se desenvolveria, depois declinaria e por fim morreria para dar lugar a um teatro mais dinâmico, mais acabado, o verdadeiro teatro do futuro.

No entanto, embora se saiba que em 1923 Copeau tenha apresentado uma divertida comédia improvisada, no teatro do Vieux Colombier, seu projeto não logrou o êxito que pretendia e ao qual se refere acima. Tratava-se da farsa de um médico, interpretado por Copeau, que tentava fazer com que um homem são se deixasse curar (CEBALLOS, 1996-1997, p. 41). A comédia parece ter divertido seu público, mas o projeto não foi levado adiante, não obstante seus estudos tenham servido em muito para os exercícios de Improvisação que introduziu em sua escola do Vieux Colombier.

Como podemos perceber alguns grandes homens do teatro francês foram fortemente influenciados por aquele estilo de representação do passado, considerado como o grande momento do ator na história do teatro ocidental, a Commedia dell'arte, e que gerou experiências muito ricas para o trabalho da Improvisação.

É interessante notar, ainda, que nesse momento Copeau rechaçava as sugestões de Jouvet com relação ao uso da mímica nos exercícios de Improvisação, pois para ele a pantomima não seria um reforço à palavra, mas outro meio de expressão, independente e ao qual, inclusive, se dedicou posteriormente e de tal modo que muitos estudiosos o consideram o "pai do mimo" moderno. Cabe também lembrar, que em sua escola do Vieux Colombier, não esqueceu do treinamento corporal, acreditando que o domínio do corpo daria ao ator a fluência da gestualidade que viria a dar vazão ao uso criativo e espontâneo da palavra.

Outro colaborador do teatro do Vieux Colombier, Charles Dullin, depois de ter também participado do processo por meio do qual Copeau pretendia uma reforma teatral, abriu em Paris seu próprio teatro, em 1921, que chamou de Atelier e que definiu como "uma nova escola para o ator". Durante o tempo em que esteve na guerra havia preparado umas pequenas peças para entreter os homens durante os períodos de repouso. Nessa ocasião conheceu Marcel Levinson, Bonnat, apelidado Bébert e Arthur Galvani, que não eram homens de teatro, mas sim artesãos que em princípio ficaram encarregados dos cenários, mas que logo começaram também a entrar em cena, demonstrando um grande talento para a Improvisação. Esse fato levou Dullin a se interessar pelo estudo da Commedia dell'arte e pelos métodos de treinamento daqueles atores. Havia percebido as possibilidades desse estilo em desenvolver 


\section{Urdimento}

4"..una escuela maravillosa para el comediante porque recurre a todas sus dotes de invención, porque suscita en él la ingeniosa utilización de todos sus medios de expresión y porque desarrolla su personalidad." no ator a plasticidade e o ritmo. Para ele, a Improvisação seria “...uma escola maravilhosa para o comediante[ou ator] porque recorre a todos os seus dotes de invenção, porque suscita nele a engenhosa utilização de todos os seus meios de expressão e porque desenvolve sua personalidade" (DULLIN, , p. 46).

No entanto, seus esforços não foram os de fazer renascer um estilo de teatro improvisado, mas sim, de utilizar a Improvisação tão somente como uma forma de treinamento. Acreditava que a Improvisação obrigaria o ator a descobrir seus próprios meios de expressão. Para tanto, sua abordagem sobre o tema abarcava dois aspectos. Em um primeiro momento do treinamento os exercícios visavam à busca interior, um trabalho "sobre si mesmo" como um meio para o crescimento pessoal do ator, no qual as sensações físicas poderiam originar memórias, analogias e sentimentos. Depois disso, então, numa segunda etapa, os exercícios deveriam levar a uma confrontação desse mundo interior com o mundo exterior. Para Dullin, o princípio da Improvisação estaria entre a "voz de si mesmo" e a "voz do mundo". Em seu Atelier pretendia chamar a atenção dos alunos sobre o que considerava uma das leis fundamentais da arte do teatro: sentir antes de tentar expressar; olhar e ver antes de querer descrever o que tiver visto; ouvir antes de responder a um interlocutor. Não era por outro motivo que Dullin recomendava a seus alunos que usassem poucas palavras em seus exercícios, procurando muito mais a expressão de estados afetivos que proviessem da observação e dos sentidos. Para Dullin, da confrontação entre "a voz do mundo" e "a voz de si mesmo" nasceria a autêntica expressão. Para tanto, os exercícios que propunha tinham ênfase no descobrimento da personalidade, sensualidade artística, sensibilidade e dons particulares. Era também uma maneira de desenvolver no aluno a autoconfiança necessária para estar em cena, pois através de tais exercícios teria a oportunidade de reconhecer seus pontos de tensão e trabalhar sobre eles. Além disso, outros exercícios eram direcionados no sentido de fazer reconhecer o tempo e o ritmo próprios do teatro, tão diferentes na vida cotidiana. O que interessava a Dullin não eram os resultados das improvisações, mas seu processo, que levaria o ator, invariavelmente, ao reconhecimento de aspectos pertinentes ao fazer teatral.

Para Dullin, através da Improvisação o ator poderia desenvolver, também, a noção da plasticidade própria do teatro. Com essa intenção introduziu também exercícios com meia-máscara para enfatizar o valor expressivo do corpo. Como tantos outros Dullin não recomendava aos seus atores apenas exercícios de Improvisação. Reconhecia o valor do treinamento corporal, que podia ser feito através do balé clássico, da dança contemporânea ou mesmo da esgrima, como meio para preparar o ator para sua mais completa expressão. Afirmava que as disciplinas coletivas com o trabalho da Improvisação, somadas 
à cultura individual, seriam os melhores meios para preparar o instrumento necessário para o desenvolvimento do teatro moderno, assim como deixava bem clara sua posição de que um treinamento deve ser sempre um meio e nunca um fim em si mesmo.

Em tempo um pouco posterior, ecos das proposições de Dullin podem ser encontrados no trabalho de Jacques Lequoc. Nascido em 1921, foi aluno de Claude Martin, que por sua vez tinha sido aluno daquele. Muitas das práticas que Lecoq pesquisou em sua escola, criada em 1956 e que permanece sendo ainda muito procurada por atores de todo o mundo, têm forte influência das idéias de Dullin. E principalmente em relação ao papel da Improvisação no treinamento do ator. Se este último recomendava o uso de poucas palavras, Lecoq, em seus exercícios iniciais chegou mesmo a suprimi-las. Sendo a Improvisação mimada, ela poderia proporcionar uma renovação da sensibilidade aos objetos e a descoberta dos momentos em que as palavras já não existem. Dullin também acreditava na expressão do silêncio, apesar de não ter pretendido suprimir por completo as palavras em suas práticas com a Improvisação.

Para Lecoq os exercícios iniciais de Improvisação têm como função dar ciência ao aluno da dimensão dramática. Partindo de propostas muito próximas da realidade dos alunos só pretende que eles consigam lhes dar vida. Depois, num segundo momento é que utiliza os jogos improvisacionais, quando o aluno já pode fazer uso de tempo, ritmo, espaço e forma teatrais; temas estes que são freqüentemente foco de seu treinamento. A descoberta do ritmo pessoal deve acompanhar a descoberta do ritmo do grupo, por exemplo. Para ele, o ritmo está na raiz de todo o jogo dramático. Os jogos de Improvisação no treinamento proposto por Lecoq, vão ganhando um grau de complexidade e estruturação cada vez maior, à medida que os alunos exercitam suas capacidades dramáticas. Para tanto, o uso da máscara neutra também faz parte dos exercícios propostos em sua escola. E também tais exercícios têm base em improvisações. Mas vale lembrar que essas improvisações, que permeiam praticamente todo o treinamento proposto por Lecoq, de maneira alguma se dão de forma aleatória. Sempre há uma condução bem clara na busca da dramaticidade que se pode descobrir com a utilização de tal recurso.

O diferencial no trabalho de preparação do ator segundo o método de Lecoq é a supressão da palavra. Para ele importa que os alunos descubram o que está mais abaixo da linguagem e que evitem o discurso explanatório. Trabalhando com a natureza humana, mas sem o uso das palavras, pretende que o ator descubra tanto os momentos em que as palavras já não são suficientes para expressar, em que há que se comunicar por outros meios, quanto os momentos em que já não há mais o que dizer. Por fim, quando o silêncio, de tão pesado, provoca a palavra, então ela pode e deve ser utilizada, 
mas aí já será fruto de uma motivação e não de impulsos aleatórios. Essa proposição, ao se dar de forma coletiva, leva o ator ao exercício do "ouvir", uma questão que Dullin já havia levantado. Para Lecoq o jogo verdadeiro só pode se fundamentar na reação de um outro, daquilo que vem de um mundo exterior, o que Dullin havia denominado de "a voz do mundo".

Fato é que, de modo geral, todos os homens do teatro realizado no século XX se valeram, de uma maneira ou de outra, da Improvisação. Fosse na preparação dos atores, fosse na dos espetáculos. No entanto, as formulações mais importantes sobre a Improvisação e sua utilização como forma de treinamento para o ator parecem ter perdido força no teatro contemporâneo, para dar lugar a uma busca mais voltada para a corporeidade. A idéia da instrumentação para um "corpo em cena” abriu caminhos para os treinamentos individuais, propiciou o alargamento dos limites corporais e as descobertas pessoais em busca da ação dramática. Disso resulta que a Improvisação passou a ser utilizada, explicitamente, quase que apenas como forma de estímulo à criação de espetáculos, em um determinado momento do processo criativo.

No entanto, podemos detectar que as proposições de Jacques Copeau ainda reverberam em alguns dos mais significativos trabalhos teatrais da contemporaneidade, como comenta Neuschäfer:

Ariane Mnouchkine não faz parte daqueles encenadores que renegam Jacques Copeau. No Texto-Programa de L'Âge d'or [A Idade do Ouro], ela lhe presta homenagem com o título de Raconter l'histoire de notre temps [Contar a História do Nosso Tempo]. Ao considerar a interrogação de Jacques Copeau como ponto de partida, ela se situa justamente em sua perspectiva, que tornava a renovação teatral incontornável. (NEUSCHÄFER, 1995, p. O2)

E ainda, como comenta Neuschäfer, a busca por formas teatrais "puras", assim referidas por Mnouchkine, são uma constante em seu trabalho, o que propiciaria uma comunicação com os atores em sua própria especificidade. E se a questão é "o vivo sentimento de estar numa época crucial, que exige a mudança do teatro” (NEUSCHÄFER, 1995, p. 02), e que para Mnouchkine necessita de

poetas que saibam dizer tudo, pintores que saibam descrever tudo e atores que sejam ao mesmo tempo pintores e poetas e saibam dar, de nosso universo abarrotado e complexo, uma representação clara e nutritiva, que saibam escrever conjuntamente, pelos seus corpos e pelas suas vozes, a comédia de nosso tempo, sem fim e sempre recomeçada (NEUSCHÄFER, 1995, p. O2), 
Talvez nossos olhares devam voltar-se para as questões relativas à Improvisação como técnica de preparação do ator, como forma de exercitarse num contexto que propicie o processo colaborativo e a aplicação de suas potencialidades em prol do conjunto da obra artística teatral.

\section{Referências bibliográficas}

CEBALLOS, E. Editorial. Máscara - cuaderno iberoamericano de reflexión sobre escenologí. México, n. 21-22, p. 3, enero 1996-1997.

Introdução a: Notas y reflexiones sobre la improvisación, de Jacques Copeau, in Máscara - cuaderno iberoamericano de reflexión sobre escenología. México, n. 21-22, p. 41, 1996-1997.

COPEAU, J. Notas y reflexiones sobre la improvisación. In: Máscara - cuaderno iberoamericano de reflexión sobre escenología. México, n. 21-22, p. 41-49, enero, 1996-1997.

DULLIN, C. Recuerdos y notas de trabajo de un actor. Trad. para o espanhol: Enriqueta Muñiz. Argentina: Libreria Hachette,

NEUSCHÄFER, Anne. «Jacques Copeau et le Théâtre du Soleil» [Jacques Copeau e O Teatro do Sol] , p. 225-231. In: PAVIS, Patrice \& THOMASSEAU, Jean-Marie (org.) Copeau l'Éveilleur [Copeau, aquele que desperta]. Lectoure: Bouffonneries n. 34, 1995. - Tradução de José Ronaldo FALEIRO. 